\title{
ECONOMIC AND POLITICAL DETERMINANTS OF TERRORISM IN SELECTED EUROPEAN COUNTRIES
}

\author{
Martin Tejkal ${ }^{1}$, Jakub Odehnal², Jaroslav Michálek ${ }^{1}$ \\ ${ }^{1}$ Department of Quantitative Methods, Faculty of Military Leadership, University of Defence, Kounicova 65, \\ 66210 Brno, Czech Republic \\ ${ }^{2}$ Department of Resources Management, Faculty of Military Leadership, University of Defence, Kounicova 65, \\ 66210 Brno, Czech Republic
}

Link to this article: https://doi.org/10.11118/actaun202068061019

Received: 21. 7. 2020, Accepted: 15. 11. 2020

To cite this article: TEJKAL MARTIN, ODEHNAL JAKUB, MICHÁLEK JAROSLAV. 2020. Economic and Political Determinants of Terrorism in Selected European Countries. Acta Universitatis Agriculturae et Silviculturae Mendelianae Brunensis, 68(6): 1019-1031.

\begin{abstract}
In this paper, we aim to assess the connection between terrorist attacks and socioeconomic and political indicators through an empirical study of selected 16 European countries. In order to reduce the dimension of the problem, factor analysis is applied in order to transform the indicator variables into factors. The countries are classified into clusters based on similarity of their economic and political indicator development, using loadings of the indicators onto the factors. For countries in each cluster, the connection of their political and socioeconomic indicators with terrorist attacks is then studied via correlation analysis of the attacks and the aforementioned factors. We propose two hypotheses - the hypothesis of opportunity costs, and the hypothesis of economic deprivation. For countries in each cluster, the hypotheses are examined with the use of correlation analysis. The results indicate that economic development affects the frequency of terrorist attacks in Belgium, France, Italy, the Netherlands, Luxembourg, Portugal, Spain, the United Kingdom, Ireland, and Switzerland.
\end{abstract}

Keywords: terrorism, opportunity costs, economic deprivation, factor analysis, correlation analysis

\section{INTRODUCTION}

At present, terrorist attacks may be considered one of the most significant security threats, as they result in loss of human lives every year. The underlying causes of modern terrorism and motivation of its perpetrators have been subject to a great deal of both theoretical and empirical research. In general, authors such as Freytag et al. (2011), Gries et al. (2011), Bravo and Dias (2006), Meierrieks and Krieger (2011), Okafor and Piesse (2018) and Caruso and Schneider (2011), base their analyses of economic factors influencing terrorist activities on existence of so-called opportunity costs and economic deprivation.
Economic determinants of terrorist attacks are analyzed in detail in Caruso and Schneider, who verified the argument of economic deprivation (more thoroughly defined in Gurr, 1970) using a group of 12 European economies. They based their study on the assumption that low economic status, low standards of living, and lack of labor market opportunities may lead to frustration of individuals, who then may incline to violence or, in extreme cases, even to terrorism. The economic environment of the analyzed countries is described using 8 variables (real GDP per capita, investment share of real GDP per capita, growth rate of real GDP per capita, unemployment rate, youth unemployment rate, inflation rate, labor productivity - GPD per hour 
worked, openness of economy). Results given by this model confirm the economic argument of opportunity costs and economic deprivation, i.e. greater economic opportunities lower the probability that individuals may be willing to perpetrate terrorism.

The authors Freytag et al. (2011) point out that the socioeconomic environment should be analyzed as a factor influencing the risk of terrorist acts. In their paper, they emphasize the importance of so-called opportunity costs, which affect decisions of potential terrorists. They analyzed a set of 110 countries using data collected between 1971 and 2007 in order to examine dependence of the number of terrorist attacks on selected economic variables (real GDP per capita, consumer spending, openness of economy, investments, economic growth). The researchers assume that individuals are more motivated to perpetrate acts of terrorism due to lower opportunity costs in countries with worse economic performance. Conclusions resulting from negative binomial regressions confirm the hypothesis about a negative relationship between the economic variables and the number of terrorist attacks in the analyzed countries.

Evidently, Gries et al. (2011), who analyzed a connection between the growth of GDP per capita and the number of terrorist acts in seven selected European countries, arrived at a similar conclusion regarding the importance of economic environment. The results confirmed that economic growth may lead to higher opportunity costs, and, in consequence, help eliminate individuals' dangerous actions.

Authors Bravo and Dias (2006), analyzed determinants of terrorist activities through so-called deprivation approach, which presumes that a low level of education, weak economy, corruption and lack of political freedom belong to key factors which affect terrorist behavior mainly in less developed countries. The researchers focused on 85 countries and 10 variables between 1997 and 2004; during this process, their aim was to prove a connection between terrorist attacks and social, political, and economic conditions of the analyzed countries. In terms of socioeconomic variables, the authors used the following ones in their regression model - index of human development, percentage of adult population with primary education, and openness of economy. Results obtained from this model confirmed the hypothesis that the highest numbers of terrorist acts are perpetrated mainly in economically less developed countries.

In their paper, Meierrieks and Krieger (2011), analyze approaches to defining determinants of terrorist activities, for which they consider mainly economic, political, institutional, and demographic factors. They discuss the economic factors mainly from the perspective of economic deprivation, which is based on the presumption that violence (in the form of terrorism) is more likely to occur at times individuals suffering from poverty and lack of economic opportunities feel frustrated. Based on the conclusion presented in Blomberg and Hess (2008), and Azam and Delacroix (2006), the authors point out the fact that favorable economic development of the specific country (measured by GDP per capita) reduces risk of potential terrorist activities. At the same time, they admit that empirical results obtained by Krueger and Malečková (2003), or Plümper and Neumayer (2010), uncover merely a weak connection between terrorist acts and economic environment of the analyzed countries.

Authors Okafor and Piesse (2018), describe determinants of terrorist attacks using an example of 38 African, Middle Eastern, and South Asian countries. They based their analysis on theory of economic deprivation, which was developed in more detail for example in Shahbaz (2013). They assume that lower standards of living of these nations, together with a low level of education and high unemployment rate create favorable matrix where terrorist ideology can thrive. For the purpose of the analysis, the authors used 8 variables (governance, fragile state, refugees, youth unemployment, foreign direct investment (FDI) per capita, foreign aid per capita, remittances and military expenditures). Their conclusions confirm that among the studied economic variables, youth unemployment has the highest level of statistical significance regarding the most significant impact on the number of terrorist attacks in the analyzed countries. As far as military expenditures as a determinant of terrorist activities are concerned, the authors expected a negative connection between the respective amount and the number of terrorist acts (more to this hypothesis can be found in Odehnal and Neubauer, 2018, who analyze terrorism as one of the determinants of military expenditures). Nevertheless, results given by their model confirmed an opposite conclusion; i.e., the amount of military expenditures has positive influence on the number of terrorist attacks. On the other hand, the authors emphasize the fact that this group consists mainly of developing countries, where data records related to military expenditures may not be fully accurate, which could partially affect the results of the analysis.

In Tab. I the key papers in which the relationship between the risk of terrorism and selected socioeconomic and political indicators is studied are collected. Furthermore, the method used in the paper as well as the authors' choice of the socioeconomic indicators is provided in the table as well.

\section{Aim of Paper}

The aim of this paper is to examine the relationship between the risk of terrorism and a set of selected indicator variables for 16 European countries by means of multidimensional statistical methods. More specifically, two concepts originating from the field of economics will be studied in the paper within the security research 
I: Key papers, applied analytical methods, and used socioeconomic and political indicator variables

\begin{tabular}{|c|c|c|}
\hline Paper & Method & Used Political and Socio Economic Indicators \\
\hline Caruso and Schneider & $\begin{array}{l}\text { Panel data model and negative } \\
\text { binomial generalized linear } \\
\text { model (GLM) }\end{array}$ & $\begin{array}{l}\text { Real GDP per capita, investments share of real GDP per capita, } \\
\text { growth rate of real GDP per capita, total unemployment rate, } \\
\text { youth unemployment rate, inflation rate, labor productivity } \\
\text { GDP, per hour worked, openness of economy }\end{array}$ \\
\hline Bravo and Dias & $\begin{array}{l}\text { Ordinary least squares (OLS) } \\
\text { regressions }\end{array}$ & Index of human development, degree of openness of economy \\
\hline Freytag et al. & $\begin{array}{l}\text { Negative binomial GLM } \\
\text { regressions }\end{array}$ & GDP per capita, consumption, trade openness, investment \\
\hline Gries et al. & $\begin{array}{l}\text { Time series analysis and } \\
\text { Granger causality test }\end{array}$ & Real GDP per capita growth \\
\hline Okafor and Piesse & $\begin{array}{l}\text { Negative binomial GLM } \\
\text { regression }\end{array}$ & Youth unemployment, FDI, military expenditures \\
\hline
\end{tabular}

framework, the concept of opportunity costs and the concept of economical deprivation. In order to do so, we propose the following two hypotheses, the hypothesis of opportunity cost $\left(\mathrm{H}_{\mathrm{oc}}\right)$, and the hypothesis of economical deprivation $\left(\mathrm{H}_{\mathrm{ed}}\right)$ :

- $\mathrm{H}_{\mathrm{oc}}$ : The stronger the economy of a country (measured by its gross domestic product), the lower the degree of motivation for terrorism.

- $\mathrm{H}_{\mathrm{ed}}$ : Increase in poverty (measured by an increase of unemployment rate) leads to a higher degree of motivation for terrorism.

The first hypothesis is built on the opportunity costs argument, in the following sense. It is assumed, that by perpetrating acts of terror in a given country, the terrorist loses the benefits connected with a life in the respective country. The stronger the economy of the country, the greater the benefit. The second hypothesis is based on the argument that economic deprivation of individuals leads to their radicalization, increasing the risk of terrorism.

\section{MATERIALS AND METHODS}

\section{Data}

The research carried out in this paper is focused on the socioeconomic and political indicators and their connection to terrorism in selected European countries. The countries discussed in this paper were chosen based on the availability of the indicator data, and the length of the time series. To be more specific, in order to obtain data prior to 1990, the countries of former Eastern bloc and countries that underwent major geopolitical changes resulting from its collapse were omitted. The following 16 European countries were considered: Austria, Belgium, Denmark, Finland, France, Greece, Ireland, Italy, Luxembourg, the Netherlands, Norway, Portugal, Spain, Sweden, Switzerland, and the United Kingdom.

For the analysis, a data set of socioeconomic and political indicators of the respective countries, and a data set containing information about the number of terrorist events over a fixed time period for each country was collected. The data set containing the annual number of terrorist attacks in a given country in the period of 1960-2017 was obtained from the Global Terrorism Database of the University of Maryland (https://www.start.umd. edu/gtd/). The data were normed for each country in order to obtain a number of attacks per 1 million inhabitants of the respective country, where by inhabitant we understand a unit of total population of a country as defined by the World Bank.

The choice of political and socioeconomic indicators was based on the studies that were mentioned in the Introduction to this paper (see Tab. I). These were further refined with respect to general availability of data and requirements of the analysis carried out for the purpose of the paper. The original set of socioeconomic and political indicator variables considered in the research is presented in Tab. II.

All data was collected in the form of yearly observations of the indicators, where the beginning of observations of individual indicators varied among the countries, and all observations ended in 2017. The government expenditure on education and the total literacy rate indicator variables proved unsuitable for the analysis due to a large number of missing observations. Additionally, the combined polity indicator variable was removed from the data set, since it was constant in the observed time period for 12 of the 16 considered countries. After these adjustments, the final set of 6 indicator variables was created. These variables served as an input for the subsequent analysis. The variables that were excluded due to the abovementioned technical issues can be found in Tab. II in bold.

For each considered country, the lowest numbers of observations were available either for the total unemployment rate or the youth unemployment rate variables, with series' starting years varying between 1981-1990 for the respective countries. Starting years of other indicator variable series (and thus their lengths) as well as the starting years of 
II: Indicator variables considered in the research; variables that had to be omitted due to various technical issues are in bold

\begin{tabular}{|c|c|c|c|}
\hline Variable name & Unit & Source & Link \\
\hline $\begin{array}{l}\text { Gross domestic product } \\
\text { (GDP) per capita }\end{array}$ & constant 2010 US\$ & World Bank Open Data & https://data.worldbank.org/ \\
\hline GDP growth & $\%$ of GDP & World Bank Open Data & https://data.worldbank.org/ \\
\hline $\begin{array}{l}\text { Govt. expenditure on } \\
\text { education }\end{array}$ & $\%$ of GDP & World Bank Open Data & https://data.worldbank.org/ \\
\hline Combined Polity & Integer Scale & Polity IV Project & http://www.systemicpeace.org/ \\
\hline $\begin{array}{l}\text { RAE Index of Electoral } \\
\text { Fractalization }\end{array}$ & Rational number & Comparative Political Data Set & https://www.cpds-data.org/ \\
\hline Regime Duration & Integer & Polity IV Project & http://www.systemicpeace.org/ \\
\hline Total literacy rate & $\%$ of people of ages $\geq 15$ & World Bank Open Data & https://data.worldbank.org/ \\
\hline Total Unemployment Rate & $\%$ of labour force & ILO & https://www.ilo.org/ \\
\hline Youth Unemployment Rate & $\%$ of labour force of age $15-24$ & ILO & https://www.ilo.org/ \\
\hline
\end{tabular}

III: Indicator time series starts, ends, and lengths

\begin{tabular}{lcccccccc}
\hline Country & Austria & Belgium & Denmark & Finland & France & Greece & Ireland & Italy \\
\hline Start & 1982 & 1983 & 1983 & 1990 & 1983 & 1981 & 1983 & 1982 \\
End & 2017 & 2017 & 2017 & 2017 & 2017 & 2017 & 2017 & 2017 \\
Length & 36 & 35 & 35 & 28 & 35 & 37 & 35 & 36 \\
\hline Country & Luxembourg & Netherlands & Norway & Portugal & Spain & Sweden & Switzerland & United Kingdom \\
\hline Start & 1983 & 1987 & 1982 & 1985 & 1986 & 1989 & 1990 & 1983 \\
End & 2017 & 2017 & 2017 & 2017 & 2017 & 2017 & 2017 & 2017 \\
Length & 35 & 31 & 36 & 33 & 32 & 29 & 28 & 35 \\
\hline
\end{tabular}

the number of terrorist attacks series were adjusted, so they would match the length of the shortest indicator observation series. In Tab. III, the unified indicator variables series' lengths are collected for each country.

\section{Statistical Methods}

The following subsections briefly describe the statistical methods applied for the purpose of this paper. More details regarding each of the methods can be found in Johnson and Wichern (2007), which was used as the main reference for the statistical analysis.

\section{Factor Analysis}

Let us denote $X=\left(X_{1}, \ldots, X_{k}\right)^{T}$ the vector of $k=6$ indicator random variables, which were described in the previous section. Note that upper right capital $\mathrm{T}$ index denotes the transposition operation. All vectors are viewed as column vectors, and handled computationally as matrices of a type $k \times 1$ unless stated otherwise. Let $\mu=E X$ be the expectation of the random vector $X$, and $\Sigma=\operatorname{var} X$ its variancecovariance matrix. Factor analysis is applied in order to describe an underlying covariance structure of the indicator variables by a set of factors. The factor model assumes that $X$ is linearly dependent on a certain number $m \leq k$ of unobservable variables $F=\left(F_{1}, \ldots, F_{m}\right)^{T}$ called common factors, and $k$ additional sources of variation $\varepsilon=\left(\varepsilon_{1}, \ldots, \varepsilon_{k}\right)^{T}$, through the following so-called standardized model

$(X-\mu) \Delta^{-\frac{1}{2}}=L F+\varepsilon$.

The term $\Delta^{-1 / 2}$ in (1) denotes a diagonal matrix, obtained by creating a diagonal matrix with the main diagonal of $\Sigma$, taking a square root of each entry, and computing an inverse. Based on the assumptions of the standardized model, it can be shown that

$\operatorname{cor} X=L L^{T}+\psi$,

where $\operatorname{cor} X$ denotes the correlation matrix of $X$. The $k \times m$ matrix $L$ is called the matrix of factor loadings, its entries $l_{i j}$ are called loadings of the $i$-th variable onto the $j$-th factor (see Johnson and Wichern, 2007).

The estimation of the parameters was carried out using the maximum likelihood method. A rotation of the original solution was obtained via the varimax method. The goal was to get as close as possible to a simple structure model, where each variable loads strongly onto a single factor. The so-called factor scores - the estimates of the factors themselves - are used in further research presented 
in this paper. The estimation of the factor scores was carried out using the regression method.

In further analysis, it is advantageous to work with just $m$ factors instead of $k$ original variables. A greater part of the information stored in the original $k$ variables is transformed into the $m$ factors; such an approach reduces the dimension of the problem while retaining most of the information stored in the original variables. This leads to more parsimonious models.

\section{Hierarchical Cluster Analysis}

The analyzed countries can be divided into groups based on the factor loadings. Each group then consists of countries with similar factor loadings. The grouping was carried out with the use of the Hierarchical Cluster Analysis (HCA). The respective loadings of each country served as its set of coordinates. Two metrics were considered to measure the distance between the countries the Euclidean metric, and the maximum metric. The distances were used as an input for the HCA algorithm, which then produced the clusters of similar countries according to the chosen intercluster distance. The considered intercluster distances were single linkage, complete linkage, centroid, and median (for details see Brieman et al., 1984).

\section{Correlation Analysis}

The correlation analysis carried out in the paper focused on studying the linear relations among variables; thus the Pearson correlation coefficient was used. The use of the correlation analysis was as follows. First, the sample correlation matrices of the indicators were computed before proceeding with the factor analysis. Then, through the coefficients of multiple correlation, it was studied how the factor scores are connected with the random variable denoted $Y$, which represents yearly numbers of terrorist attacks per 1 million of inhabitants. Finally, the two hypotheses presented in the Introduction were studied using correlation coefficients of $Y$, and $m$ factors $F_{1}, \ldots, F_{m}$. For the sake of completeness, we provide the definition of the sample coefficient of multiple correlation that was used in the analysis.

Let $R_{Y, F_{1}, \ldots, F_{m}}$ be the type $m+1 \times m+1$ correlation matrix of variables $Y, F_{1}, \ldots, F_{m}$. Denote
$R_{Y, F}=\left(r_{Y, F_{1}}, \ldots, r_{Y, F_{m}}\right)$ the type $1 \times m+1$ submatrix of $R_{Y, F_{1}, \ldots, F_{m}}$, obtained by removing all but the first row of $\boldsymbol{R}_{Y, F_{1}, \ldots, F_{m}}$, and $\boldsymbol{R}_{F, Y}=\boldsymbol{R}_{Y, F}^{T}=\left(r_{F_{1}, Y}, \ldots, r_{F_{m, Y},{ }^{T}}\right)^{T}$ a type $m+1 \times 1$ submatrix obtained by removing all but the first column of $R_{Y, F_{1}, \ldots, F_{m}}$. Finally a submatrix of $R_{Y F_{1}, \ldots F_{m}}$ obtained by removing the first column and the first row will be denoted $R_{F, F}$. This matrix is in fact the correlation matrix of the factors. The sample coefficient of multiple correlation is given by

$r_{Y, F}=\sqrt{R_{Y, F} R_{F, F}^{-1} R_{F, Y}}$.

The significance of the entries of the correlation matrix as well as of the coefficient of multiple correlation was tested at the significance level of $\alpha=0.05$.

When testing the significance of the entries of the correlation matrix, the null hypothesis is $H_{0}: \rho_{X_{i}{ }_{X}}=0$. This hypothesis was tested separately for each $i, j \in\{1, \ldots, 6\}$ and for each country, except for the cases when $i=j$, where it would be redundant. The respective test statistic is given by

$T=\frac{r_{X_{i} X_{j}}}{\sqrt{1-r_{X_{i} X_{j}}^{2}}} \sqrt{n_{\text {count }}-2}$

where $n_{\text {count }}$ denotes the sample size of the indicator data sample for the respective country. It can be shown that under the null hypothesis, (4) has student $t$ distribution with $n_{\text {count }}$ - 2 degrees of freedom (see Rao, 1973).

When testing the significance of the multiple correlation coefficients between $Y$ and the $m$ factors $F_{1}, \ldots, F_{m}$, the null hypothesis is $H_{0}: \rho_{Y F}=0$. This hypothesis was tested for each country. The respective test statistic is given by

$Z=\frac{n_{\text {count }}-m-1}{m} \frac{r_{Y, F}^{2}}{1-r_{Y, F}^{2}}$.

The test statistic (5) has a Fisher-Snedecor distribution with degrees of freedom $d f_{1}=m$ and $d f_{2}=n_{\text {count }}-\mathrm{m}-1$ (for details see Rao, 1973).

\section{RESULTS}

In this section, the results of the statistical analysis of the data set are presented.

IV: CPSV for the two factor model

\begin{tabular}{lcccccccc}
\hline Country & Austria & Belgium & Denmark & Finland & France & Greece & Ireland & Italy \\
\hline Factor 1 & 0.394 & 0.466 & 0.361 & 0.390 & 0.374 & 0.547 & 0.451 & 0.328 \\
Factor 2 & 0.785 & 0.589 & 0.687 & 0.707 & 0.736 & 0.819 & 0.794 & 0.654 \\
\hline Country & Luxembourg & Netherlands & Norway & Portugal & Spain & Sweden & Switzerland & United Kingdom \\
\hline Factor 1 & 0.473 & 0.456 & 0.407 & 0.405 & 0.407 & 0.426 & 0.394 & 0.509 \\
Factor 2 & 0.749 & 0.791 & 0.765 & 0.787 & 0.787 & 0.758 & 0.726 & 0.788 \\
\hline
\end{tabular}


V: CPSV for the three factor model

\begin{tabular}{lcccccccc}
\hline Country & Austria & Belgium & Denmark & Finland & France & Greece & Ireland & Italy \\
\hline Factor 1 & 0.391 & 0.422 & 0.335 & 0.344 & 0.364 & 0.347 & 0.454 & 0.330 \\
Factor 2 & 0.713 & 0.552 & 0.632 & 0.669 & 0.711 & 0.614 & 0.778 & 0.658 \\
Factor 3 & 0.813 & 0.672 & 0.815 & 0.847 & 0.828 & 0.843 & 0.916 & 0.814 \\
\hline Country & Luxembourg & Netherlands & Norway & Portugal & Spain & Sweden & Switzerland & United Kingdom \\
\hline Factor 1 & 0.485 & 0.439 & 0.339 & 0.410 & 0.371 & 0.433 & 0.373 & 0.425 \\
Factor 2 & 0.728 & 0.759 & 0.676 & 0.786 & 0.712 & 0.753 & 0.614 & 0.706 \\
Factor 3 & 0.782 & 0.933 & 0.805 & 0.802 & 0.902 & 0.926 & 0.832 & 0.809 \\
\hline
\end{tabular}

Factor Analysis Results - Principal Factors

With the use of the factor analysis, the loadings of all the indicators onto the factors were estimated for each country. Then the proportion of total sample variance (PSV) due to each factor was calculated. In this paper, a two factor and a three factor models were considered. The cumulative proportion of sample variance (CPSV) of the considered factor models is presented in Tabs. IV and V.

The tables show that the cumulative proportion of the sample variance of the two factor model never drops below 0.5. The lowest value of cumulative variance explained by the factor model is for both the two and the three factor models attained for Belgium, where for the two factor model $C P S V_{\text {ol } 2}=0.589$, and for the three factor model $C P S V_{\text {bel, } 3}=0.672$.

From now on, attention will be paid to the two factor model. The loadings of the indicator variables onto each of the two factors for each country are collected in Tab. VI.

\section{Results of Clustering}

The HCA was used in order to obtain groups (clusters) of countries with similar values of socioeconomic and political indicator variables. This similarity was expressed by similar loading patterns in the factor loadings of the countries. The result of the HCA applied to the loadings of the countries obtained through the factor analysis is presented via dendrograms in Figs. 1 and 2. Because the factor loadings are continuous numerical variables, the Euclidean metric was used to describe the distance between countries in terms of estimated factor loadings. Then the single linkage (nearest neighbor) and robust median distance was used as intercluster distance (dissimilarity measure).

Dendrograms presented in Figs. 1 and 2 suggest a similar clustering. The countries can be divided into two branches. Furthermore, it can be noticed that in the left branch, Belgium differs more substantially from the rest of the cluster. Similarly in the right branch, Luxembourg and Switzerland differ from the rest more substantially (dissimilarity measure (denoted "height" in Figs. 1 and 2) greater than 1). On that account, Belgium, Luxembourg, and Switzerland will be considered a different cluster from the rest of the countries in the two respective branches, and handled separately. The remaining countries, whose dissimilarity measure is lower than one in Figs. 1 and 2, will be split into two separate clusters. The first of the clusters will be denoted as cluster A, and will consist of Austria, Denmark, Finland, Ireland, Italy, the Netherlands, Norway, Sweden, and the United Kingdom. The second one will be denoted cluster B, and will consist of France, Greece, Portugal, Spain. Furthermore, cluster A will be split into two subclusters denoted based on the dissimilarity measure. The first will be denoted subcluster Aa, and will consist of Denmark, Finland, Ireland, Italy, the Netherlands, and the United Kingdom. The second one will be denoted subcluster Ab, and will consist of Austria, Norway, and Sweden.

\section{Results of Correlation Analysis of Countries of Cluster B}

Let us start by describing the results obtained for the countries constituting cluster B. These were France, Greece, Portugal, and Spain. For this group of countries, the RAE electoral fractalization index, the total unemployment rate, and the youth unemployment rate load strongly positively onto the first factor, while GDP per capita and regime duration load positively onto the second factor. Additionally, for France and Greece the RAE electoral fractalization index loads strongly positively onto the first factor. Apart from these deviations, a similar pattern of loadings can be observed for cluster B countries. Let us introduce the following notation. The factor with strong loadings of GDP per capita and regime duration will be called the factor of economic strength and political stability of cluster B, and the factor with strong loadings of unemployment rates will be called the labor market factor of cluster B. The factor of economic strength and political stability of cluster B represents the economic strength and stability of the country, while the labor market factor of cluster B represents the job security and personal wealth and well-being of citizens of the given country. 
VI: A table of loadings of the indicator variables on the factors of the two factor model for each country. Values of loadings whose absolute values are greater than 0.7 are in bold. In further analysis, the countries will be separated into clusters, which is reflected in this table as well by the respective row

\begin{tabular}{|c|c|c|c|c|c|c|c|c|}
\hline Country & \multicolumn{2}{|c|}{ Austria } & \multicolumn{2}{|c|}{ Belgium } & \multicolumn{2}{|c|}{ Denmark } & \multicolumn{2}{|c|}{ Finland } \\
\hline Cluster & \multicolumn{2}{|c|}{$\mathrm{Ab}$} & \multicolumn{2}{|c|}{ Separate } & \multicolumn{2}{|c|}{$\mathrm{Aa}$} & \multicolumn{2}{|c|}{$\mathrm{Aa}$} \\
\hline Factor & Factor 1 & Factor 2 & Factor 1 & Factor 2 & Factor 1 & Factor 2 & Factor 1 & Factor 2 \\
\hline GDP growth & -0.14 & -0.279 & -0.133 & -0.22 & -0.262 & -0.088 & 0.006 & 0.379 \\
\hline GDP p. capita & 0.795 & 0.584 & 0.976 & 0.184 & 0.936 & -0.341 & 0.886 & -0.304 \\
\hline RAE e. f. & 0.860 & 0.312 & 0.535 & 0.014 & 0.302 & 0.386 & 0.574 & -0.128 \\
\hline Regime dur. & 0.804 & 0.590 & 0.953 & 0.296 & 0.994 & -0.088 & 0.995 & -0.077 \\
\hline T. unemp. rate & 0.397 & 0.808 & -0.784 & 0.214 & -0.375 & 0.887 & -0.371 & 0.926 \\
\hline Y. unemp. rate & 0.410 & 0.909 & -0.144 & 0.721 & 0.033 & 0.915 & -0.319 & 0.887 \\
\hline Country & \multicolumn{2}{|c|}{ France } & \multicolumn{2}{|c|}{ Greece } & \multicolumn{2}{|c|}{ Ireland } & \multicolumn{2}{|c|}{ Italy } \\
\hline Cluster & \multicolumn{2}{|c|}{$\mathrm{B}$} & \multicolumn{2}{|c|}{$\mathrm{B}$} & \multicolumn{2}{|c|}{$\mathrm{Aa}$} & \multicolumn{2}{|c|}{$\mathrm{Aa}$} \\
\hline Factor & Factor 1 & Factor 2 & Factor 1 & Factor 2 & Factor 1 & Factor 2 & Factor 1 & Factor 2 \\
\hline GDP growth & 0.176 & -0.252 & -0.378 & 0.018 & 0.075 & -0.289 & -0.505 & 0.069 \\
\hline GDP p. capita & -0.042 & 0.997 & -0.02 & 0.997 & 0.926 & -0.337 & 0.846 & -0.28 \\
\hline RAE e. f. & 0.749 & 0.196 & 0.908 & 0.215 & 0.829 & -0.172 & -0.014 & 0.134 \\
\hline Regime dur. & 0.029 & 0.977 & 0.654 & 0.729 & 0.991 & -0.114 & 0.989 & 0.134 \\
\hline T. unemp. rate & 0.952 & -0.296 & 0.978 & 0.197 & -0.408 & 0.910 & -0.143 & 0.917 \\
\hline Y. unemp. rate & 0.861 & -0.182 & 0.964 & 0.145 & -0.066 & 0.995 & -0.026 & 0.997 \\
\hline Country & \multicolumn{2}{|c|}{ Luxembourg } & \multicolumn{2}{|c|}{ Netherlands } & \multicolumn{2}{|c|}{ Norway } & \multicolumn{2}{|c|}{ Portugal } \\
\hline Cluster & \multicolumn{2}{|c|}{ Separate } & \multicolumn{2}{|c|}{$\mathrm{Aa}$} & \multicolumn{2}{|c|}{$\mathrm{Ab}$} & \multicolumn{2}{|c|}{$\mathrm{B}$} \\
\hline Factor & Factor 1 & Factor 2 & Factor 1 & Factor 2 & Factor 1 & Factor 2 & Factor 1 & Factor 2 \\
\hline GDP growth & -0.444 & -0.078 & -0.406 & -0.012 & -0.351 & 0.258 & -0.327 & -0.508 \\
\hline GDP p. capita & 0.580 & 0.803 & 0.939 & -0.328 & 0.994 & 0.081 & -0.035 & 0.997 \\
\hline RAE e. f. & 0.045 & 0.634 & 0.796 & -0.267 & 0.640 & 0.575 & 0.632 & 0.019 \\
\hline Regime dur. & 0.725 & 0.673 & 0.986 & -0.112 & 0.960 & 0.020 & 0.381 & 0.915 \\
\hline T. unemp. rate & 0.979 & 0.192 & -0.287 & 0.956 & 0.007 & 0.864 & 0.935 & 0.330 \\
\hline Y. unemp. rate & 0.905 & 0.337 & -0.048 & 0.952 & -0.005 & 0.997 & 0.949 & 0.307 \\
\hline Country & \multicolumn{2}{|c|}{ Spain } & \multicolumn{2}{|c|}{ Sweden } & \multicolumn{2}{|c|}{ Switzerland } & United & ngdom \\
\hline Cluster & & & & & Sep & ate & & \\
\hline Factor & Factor 1 & Factor 2 & Factor 1 & Factor 2 & Factor 1 & Factor 2 & Factor 1 & Factor 2 \\
\hline GDP growth & -0.378 & -0.428 & 0.121 & 0.142 & 0.043 & 0.277 & -0.352 & -0.08 \\
\hline GDP p. capita & -0.387 & 0.919 & 0.976 & 0.184 & 0.467 & 0.881 & 0.945 & -0.319 \\
\hline RAE e. f. & 0.441 & -0.111 & 0.801 & -0.01 & -0.284 & -0.599 & 0.824 & 0.064 \\
\hline Regime dur. & 0.026 & 0.997 & 0.930 & 0.349 & 0.645 & 0.747 & 0.971 & -0.170 \\
\hline T. unemp. rate & 0.983 & -0.048 & -0.057 & 0.996 & 0.959 & 0.211 & -0.618 & 0.771 \\
\hline Y. unemp. rate & 0.994 & 0.092 & 0.285 & 0.907 & 0.854 & 0.418 & 0.189 & 0.967 \\
\hline
\end{tabular}

Using the correlation analysis, we found a significant relationship between the number of terrorist attacks time series and the factor scores for most countries of cluster B (see Tab. VII). The coefficient of multiple correlation differed significantly from zero for France, Portugal, and
Spain at the significance level of $\alpha=0.05$. In fact, out of the 16 countries considered in the study, the connection between the number of terrorist attacks and the two respective factors is the strongest in case of France, Portugal, and Spain. 


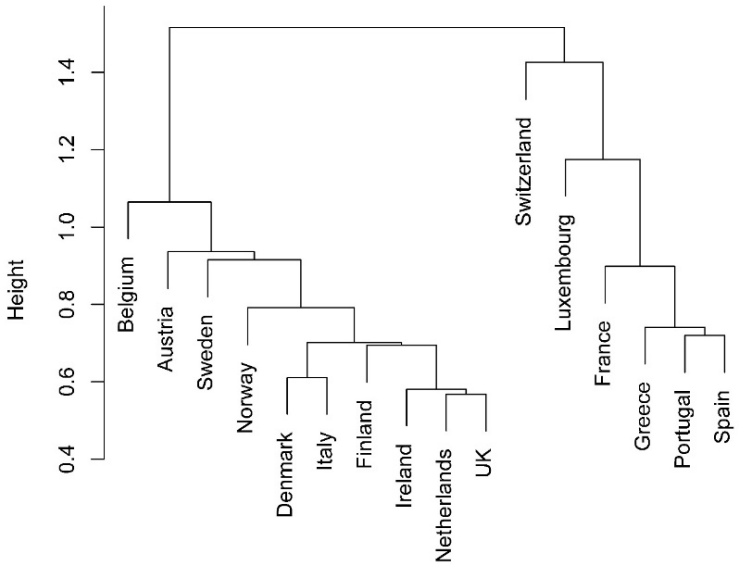

Metric: euclidean, Intercluster distance: single linkage

1: A dendrogram created using the Euclidean metric and single linkage distance. Height represents the distance (dissimilarity measure) between factor loadings of the merging countries.

In order to examine the two hypotheses listed at the beginning of the paper, it is necessary to study the correlation of the terrorist attacks time series with each of the factors separately. The respective sample correlation coefficients are provided in Tab. VII together with their test of significance (see (4)) p-values. As mentioned above, the first factor was identified as the labor market factor of cluster B, and represented job security, personal wealth and well-being of citizens. On that account, if the labor market factor of cluster B was significantly positively correlated with the number of terrorist attacks, it would support the validity of the hypothesis of economic deprivation. For France, Portugal, and Spain, we do not reject the hypothesis of nullity of $r_{Y, F_{1}}$ at $\alpha=0.05$. This means that for the respective countries, there is not enough evidence in the data sample that labor market factor of cluster $\mathrm{B}$ is connected to the number of terrorist attacks, and, therefore, not enough evidence that would support neither the validity nor invalidity of the hypothesis of economic deprivation.

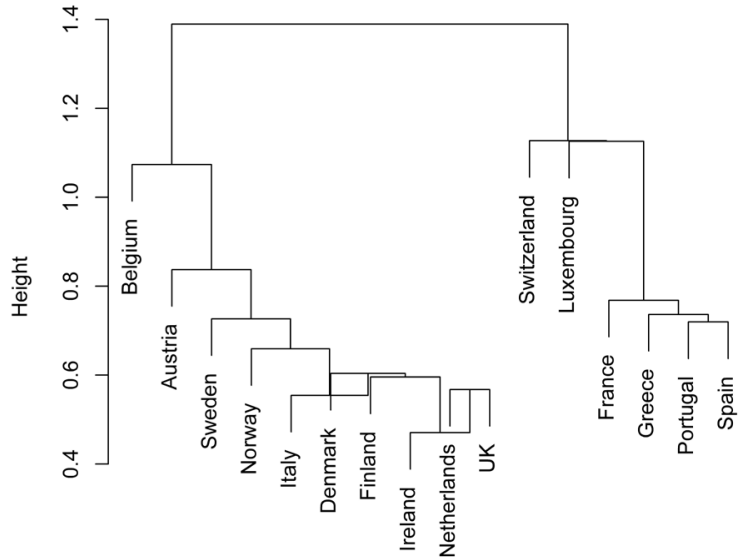

Metric: euclidean, Intercluster distance: median

2: A dendrogram created using the Euclidean metric and median intercluster distance. Height represents the distance (dissimilarity measure) between factor loadings of the merging countries.

On the other hand, we reject the hypothesis of nullity of the correlation coefficient $r_{Y, F_{2}}$ for France, Portugal, and Spain at $\alpha=0.05$. As mentioned before, the second factor was identified for cluster $B$ as the factor of economic strength and political stability that represents economic strength and stability of the country. On that account, this factor was significantly negatively correlated with the number of attacks series; it would mean that with increasing economic strength of the country the number of attacks decreased, thus there is enough evidence to support the hypothesis of opportunity costs. In fact, the sample correlation coefficients $r_{Y, F_{2}}$ are negative for the three countries, and for each of the three sample coefficients we reject the nullity hypothesis at $\alpha=0.05$. On that account, we conclude that there is evidence in the data that supports validity of the hypothesis of opportunity costs for France, Portugal, and Spain.

Last but not least, let us discuss the results obtained for the last member of cluster B, which is Greece. In case of Greece, the hypothesis of nullity

VII: Sample coefficients of multiple correlation $r_{Y, F_{1} F_{F}}$, and sample correlation coefficients $r_{Y, F_{1}}$, and $r_{Y, F_{2}}$ of cluster $B$ together with the results of significance tests of the respective coefficients (see subsection 2.2.3) at the significance level of $\alpha=0.05$ (significance codes: ${ }^{* * *}$ significant at $\alpha=0.001 ;{ }^{* *}$ significant at $\alpha=0.01 ;{ }^{*}$ significant at $\alpha=0.05 ; \cdot$ significant at $\alpha=0.1$ )

\begin{tabular}{lcccc}
\hline \multicolumn{1}{r}{ Country } & France & Greece & Portugal & Spain \\
\hline \multicolumn{1}{c}{ Cluster } & $\mathrm{B}$ & $\mathrm{B}$ & $\mathrm{B}$ & $\mathrm{B}$ \\
\hline$r_{Y ; F_{1}, F_{2}}$ & 0.634 & 0.030 & 0.646 & 0.830 \\
$\mathrm{p}$-value & $0.000^{* * *}$ & 0.985 & $0.000^{* * *}$ & $0.000^{* * *}$ \\
$r_{Y, F_{1}}$ & 0.225 & 0.023 & 0.250 & -0.036 \\
$\mathrm{p}$-value & 0.193 & 0.892 & 0.161 & 0.847 \\
$r_{Y, F_{2}}$ & -0.593 & 0.018 & -0.596 & -0.829 \\
$\mathrm{p}$-value & $0.000^{* * *}$ & 0.914 & $0.000^{* * *}$ & $0.000^{* * *}$ \\
\hline
\end{tabular}


of the coefficient of multiple correlation $r_{Y, F_{1}, F_{2}}$ was not rejected at $\alpha=0.05$, and neither were the hypotheses of nullity of both sample correlations $r_{Y, F_{1}}$ and $r_{Y, F_{2}}$ at $\alpha=0.05$. For this reason, it may be argued that for Greece, no significant evidence of connection between the terrorist attacks and either of the two factors was found in the available data using the described methods. Furthermore, there was not enough evidence which would support validity or invalidity of either of the two hypotheses stated in the introductory section of this paper. There are two possible explanations why no relation or evidence thereof was found in case of Greece. The simplest one is that there is, in fact, no relation to be found. Nevertheless, the reason might as well be that the used method was not able to discover the relation. The sample variance of terrorist attacks normed yearly observations sample for Greece was the second highest out of the 16 countries, surpassed only by the one for Luxembourg. This suggest a great variability in the data. Additionally, the functional relation between the attacks and either of the factors might not be linear; therefore, the linear correlation analysis might have not discovered it.

\section{Results of Correlation Analysis of Countries of Cluster A}

As mentioned previously, cluster A was further split into two subclusters. Where it proves necessary, the results will be discussed for each of the subclusters separately. If the results do not differ for the two subclusters, they will be discussed for both of them together.

For subcluster Aa, GDP per capita and regime duration load strongly positively onto the first factor. Additionally, for Finland, the Netherlands, Ireland, and the United Kingdom, the RAE electoral fractalization index loads strongly positively onto the first factor. In case of Denmark and Italy, only GDP per capita and regime duration load strongly positively onto the first factor. Total unemployment rate and youth unemployment rate are the only two variables that load strongly onto the second factor of the countries of subcluster Aa; the respective loadings are positive. Among the countries of subcluster Ab, Norway has a loading pattern which is most similar to the countries of subcluster Aa. GDP per capita and regime duration load strongly positively onto the first factor for Norway. In case of Sweden and Austria, GDP per capita, regime duration, and RAE electoral fractalization index load strongly positively onto the first factor. For all the countries of subcluster $\mathrm{Ab}$, total unemployment rate and youth unemployment rate load strongly positively onto the second factor.

Similarly, in cluster B, it is also possible to recognize a pattern in the loadings of the two factors. The variables loading strongly positively onto the first factor of the countries of cluster A are GDP per capita and regime duration, and for some countries also RAE electoral fractalization index. On that account, it will be henceforth denoted the factor of economic strength and political stability of cluster A. The variables loading strongly positively onto the second factor are total unemployment rate and youth unemployment rate. The second factor for cluster A will be henceforth denoted the labor market factor of cluster A, and will be interpreted as a factor representing job security, personal wealth and well-being of citizens of the respective countries.

The results of the correlation analysis of cluster $\mathrm{A}$ are summarized in Tab. VIII for subcluster Aa, and Tab. IX for subcluster Ab. We reject the hypothesis of nullity of the coefficient of multiple correlation at the significance level of $\alpha=0.05$ for the following countries: Austria, Ireland, Italy, the Netherlands, and the United Kingdom. For these countries, there is a significant connection between the number of terrorist attacks and the two factors. When taking a closer look at the respective subclusters, one can notice that in subsubcluster $\mathrm{Aa}$, the connection between the number of terrorist attacks and the two factors is stronger than in subcluster Ab.

In order to examine the two hypotheses from the introductory section, it is again necessary to look at the sample correlation coefficients of the number of the terrorist attacks and each of the two respective factors. Based on the introduced notation, if the factor of economic strength and political stability

VIII: Sample coefficients of multiple correlation $r_{Y, F_{1}, F_{2}}$, and sample correlation coefficients $r_{Y, F_{1}}$, and $r_{Y, F_{2}}$ of subcluster Aa together with results of significance tests of the respective coefficients (see subsection 2.2.3) at the significance level of $\alpha=0.05$ (significance codes: ${ }^{* * *}$ significant at $\alpha=0.001 ;{ }^{* *}$ significant at $\alpha=0.01 ; *$ significant at $\alpha=0.05 ; \cdot$ significant at $\alpha=0.1$ )

\begin{tabular}{lcccccc}
\hline Country & Denmark & Finland & Ireland & Italy & Netherlands & Un. King. \\
\hline \multicolumn{1}{c}{ Cluster } & Aa & Aa & Aa & Aa & Aa & Aa \\
\hline$r_{Y, F_{1}, F_{2}}$ & 0.225 & 0.386 & 0.600 & 0.455 & 0.516 & 0.512 \\
p-value & 0.436 & 0.134 & $0.001^{* *}$ & $0.022^{*}$ & $0.013^{*}$ & $0.008^{* *}$ \\
$r_{Y, F_{1}}$ & -0.189 & 0.370 & 0.383 & -0.453 & -0.471 & -0.488 \\
p-value & 0.277 & $0.053 \cdot$ & $0.023^{*}$ & $0.006^{* *}$ & $0.007^{* *}$ & $0.003^{* *}$ \\
$r_{Y, F_{2}}$ & 0.123 & 0.109 & 0.461 & 0.051 & 0.213 & 0.155 \\
p-value & 0.480 & 0.579 & $0.005^{* *}$ & 0.767 & 0.250 & 0.373 \\
\hline
\end{tabular}


IX: Sample coefficients of multiple correlation $r_{Y, F_{1} F_{2}}$, and sample correlation coefficients $r_{Y, F}$, and $r_{Y, F_{2}}$ of the subcluster Ab together with results of significance tests of the respective coefficients (see subsection 2.2.3) at the significance level of $\alpha=0.05$ (significance codes: ${ }^{* * *}$ significant at $\alpha=0.001 ;{ }^{* *}$ significant at $\alpha=0.01 ;{ }^{*}$ significant at $\alpha=0.05 ; \cdot$ significant at $\alpha=0.1$ )

\begin{tabular}{lcccc}
\hline & Country & Austria & Norway & Sweden \\
\hline & Cluster & $\mathrm{Ab}$ & $\mathrm{Ab}$ & $\mathrm{Ab}$ \\
\hline$r_{Y ; F_{1}, F_{2}}$ & 0.423 & 0.080 & 0.337 \\
$\mathrm{p}$-value & $0.039^{*}$ & 0.899 & 0.209 \\
$r_{Y, F_{1}}$ & -0.319 & -0.06 & 0.327 \\
$\mathrm{p}$-value & $0.058 \bullet$ & 0.730 & $0.083 \bullet$ \\
$r_{Y, F_{2}}$ & -0.283 & 0.054 & -0.079 \\
$\mathrm{p}$-value & $0.095 \bullet$ & 0.756 & 0.683 \\
\hline
\end{tabular}

of cluster A is significantly negatively correlated with the number of terrorist attacks, it suggests that the hypothesis of opportunity costs holds. The fact that labor market factor of cluster A is significantly positively correlated with the number of terrorist attacks could serve as factual evidence suggesting the validity of the hypothesis of economic deprivation.

In case of subcluster Aa, the hypothesis of nullity of the correlation coefficient $r_{Y, F_{1}}$ at $\alpha=0.05$ was rejected for the following countries: Ireland, Italy, the Netherlands, and the United Kingdom. For Italy, the Netherlands, and the United Kingdom $r_{Y, F_{1}}$ is negative; for Ireland $r_{Y, F_{1}}$ is positive. For Italy, the Netherlands, and the United Kingdom we thus conclude that there is factual evidence to support the hypothesis of opportunity costs. Nonetheless, the results suggest that for Ireland, the opposite holds - with increasing economic strength, the risk of terrorism increases as well. For the remaining countries of subcluster Aa we conclude that there is not enough evidence to support neither validity nor invalidity of the hypothesis of opportunity costs. Moreover, among the countries of subcluster Aa, the hypothesis of nullity of $r_{Y, F_{2}}$ is rejected at $\alpha=0.05$ only in case of Ireland. For Ireland, the value of $r_{Y, F_{2}}$ is positive. On that account, we conclude that out of the countries of subcluster Aa, the data contains factual evidence supporting validity of the hypothesis of economic deprivation only in case of Ireland. As far as other countries of subcluster $\mathrm{Aa}$ are concerned, we conclude that there is not enough evidence to support neither validity nor invalidity of the hypothesis of economic deprivation.

Let us focus on subcluster $\mathrm{Ab}$ of cluster $\mathrm{A}$. As mentioned before, the relation between the number of terrorist attacks and the respective factors was weaker for subcluster $\mathrm{Ab}$ than for subcluster Aa. This is further represented by the fact that we do not reject the hypotheses of nullity of $r_{Y, F_{1}}$ or of $r_{Y, F_{2}}$ for any of the countries at $\alpha=0.05$. Nevertheless, it should be mentioned that for Austria, the p-value of the test of nullity of $r_{Y, F_{1}}$ attains a fairly borderline value (see Tab. IX). We, however, conclude that there is no significant evidence in the data that would support neither validity nor invalidity of either the first or the second hypothesis for countries of subcluster $\mathrm{Ab}$.

\section{Results of Correlation Analysis of Belgium, Luxembourg, and Switzerland}

In this section, attention will be paid to the three countries that did not fit properly into either of the two clusters - Belgium, Luxembourg, and Switzerland. In case of Belgium, GDP per capita and regime duration load strongly positively onto the first factor, which is similar to the countries of cluster A. Nonetheless, the youth unemployment rate loads strongly negatively onto the first factor, which deviates from the loading pattern of cluster A. In turn, only the youth unemployment rate loads strongly positively onto the second factor, which further differentiates Belgium from countries of cluster A.

In case of Belgium, the first factor contains both the information about economic strength and stability of the country (provided by GDP per capita and regime duration) and job security and economic well-being of the population (provided by the total unemployment rate). The second factor then contains information about job security and economic well-being of a certain part of the population - the young people.

For Belgium, we reject the hypothesis of nullity of the coefficient of the multiple correlation at $\alpha=0.05$. On that account, we conclude that there is a significant relationship between the two factors and the number of terrorist attacks (see Tab. X). In order to examine the two hypotheses presented in the introductory section, we will focus on the correlation coefficient $r_{Y F_{1}}$, since it contains both the information about economic strength and stability of Belgium, and job security and economic wellbeing of its citizens. The value of $r_{Y F_{1}}$ is negative, and we reject the hypothesis of nullity of $r_{Y, F_{1}}$ at $\alpha=0.05$. Thereupon, we conclude that in case of Belgium, there is factual evidence in favor of validity of both hypotheses of opportunity costs and economic deprivation (see Tab. X). 
$\mathrm{X}$ : Sample coefficients of multiple correlation $r_{Y, F_{1} F_{2}}$, and sample correlation coefficients $r_{Y, F_{1}}$, and $r_{Y, F_{2}}$ of Belgium, Luxembourg, and Switzerland together with results of the slgnificance tests of the respective coefficients (see subsection 2.2.3) at the significance level of $\alpha=0.05$ (significance codes: ${ }^{* * *}$ significant at $\alpha=0.001 ; * *$ significant at $\alpha=0.01 ; *$ significant at $\alpha=0.05$; - significant at $\alpha=0.1$ )

\begin{tabular}{|c|c|c|c|}
\hline Country & Belgium & Luxembourg & Switzerland \\
\hline Cluster & - & - & - \\
\hline$r_{Y ; F_{1}, F_{2}}$ & 0.568 & 0.505 & 0.478 \\
\hline p-value & $0.002^{* *}$ & $0.009 * *$ & $0.039 *$ \\
\hline$r_{Y, F_{1}}$ & -0.565 & -0.001 & -0.392 \\
\hline $\mathrm{p}$-value & $0.000^{* * *}$ & 0.993 & $0.039 *$ \\
\hline$r_{Y, F_{2}}$ & 0.006 & -0.505 & -0.283 \\
\hline $\mathrm{p}$-value & 0.971 & $0.002 * *$ & 0.144 \\
\hline
\end{tabular}

In case of Belgium, it would also be possible to further analyze $r_{Y, F_{2}}$ in order to discuss a hypothesis whether job security and economic well-being of a certain group of its population (namely, the young people) affect the number of terrorist attacks. Nevertheless, we do not reject the hypothesis of nullity of $r_{Y, F_{2}}$ at $\alpha=0.05$ and, therefore, conclude that the data does not contain enough evidence to support the fact that job security and economic well being of young people lead to a significant decrease or increase of frequency of terrorist attacks in Belgium.

Let us focus on Luxembourg and Switzerland. In case of Luxembourg, total unemployment rate and youth unemployment rate load strongly positively onto the first factor, which is fairly typical for countries of cluster B. Moreover, regime duration loads strongly positively onto the first factor as well. This fact distinguishes the first factor loadings from the rest of cluster B countries. Out of the loadings onto the second factor, only the absolute value of GDP per capita loading exceeds the 0.7 threshold. It is necessary to emphasize that this loading is positive. This further differentiates Luxembourg from the rest of cluster B, where the 0.7 threshold is usually exceeded by regime duration as well.

The first factor contains the information about labor market, personal wealth and opportunities of the citizens. As for Luxembourg, it is interesting that this is in the first factor followed by the information about regime duration.

The second factor contains information about economic strength of the country measured in GDP per capita.

For Luxembourg, we reject the hypothesis of nullity of the coefficient of the multiple correlation at $\alpha=0.05$. On that account, we conclude that there is a significant relationship between the two factors and the number of terrorist attacks.

In order to examine the hypothesis of economic deprivation, we would examine the correlation of the factor with strong loadings of the two unemployment rate indicators with the number of terrorist attacks series. In case of Luxembourg, this means focusing on the first factor. The value of $r_{Y, F_{1}}$ is negative; however, at $\alpha=0.05$ we do not reject the hypothesis of nullity of $r_{Y, F_{1}}$, which suggests there is not enough evidence in the data to support neither validity nor invalidity of the hypothesis of economic deprivation. What makes the interpretation more complicated is the fact that the first factor of Luxembourg is loaded upon strongly by regime duration, which is a variable typically associated with the hypothesis of opportunity costs for all other countries studied in this paper. This interplay may affect the result of the significance test of the respective correlation coefficient.

In order to examine the hypothesis of opportunity costs, we will focus on coefficient $r_{Y, F_{F}}$. The value of $r_{Y, F_{2}}$ is negative, which means that if $r_{Y, F_{2}}$ differs significantly from zero, the number of terrorist attacks decreases as the values of $F_{2}$ increase. Indeed, for $\alpha=0.05$, we reject the hypothesis of nullity of $r_{Y F_{F}}$, and subsequently conclude that there is factual evidence supporting the hypothesis of opportunity costs.

Finally, as for Switzerland, the total unemployment rate and youth unemployment rate load strongly positively onto the first factor, while GDP per capita and regime duration load strongly positively onto the second factor. This resembles the loadings of the rest of cluster B. The reason why Switzerland differs more from France, Greece, Portugal, and Spain are loadings of several other variables, whose absolute values do not exceed the 0.7 threshold; namely, the positive loading of regime duration onto the first factor, or the negative loading of RAE electoral fractalization index onto the second factor. These relatively high loadings complicate the interpretation of the factors, although it is possible to recognize a loading pattern somewhat similar to the rest of cluster B, where the first factor was interpreted as the one carrying information about job security and economic well-being of citizens of the country, while the second factor was interpreted as the one carrying information about economic strength and stability of the country. 
For Switzerland, we reject the hypothesis of nullity of the coefficient of multiple correlation for $\alpha=0.05$. On that account, we conclude that there is a significant correlation between the number of terrorist attacks and the two respective factors.

In order to test the hypotheses from the introductory part of this paper, we will take a closer look at the values of the correlation coefficients $r_{Y, F_{1}}$ and $r_{Y, F_{2}}$ again. The value of $r_{Y, F_{1}}$ is negative, and for $\alpha=0.05$, we reject the hypothesis of nullity of $r_{Y, F_{1}}$. Consequently, we conclude that there is factual evidence in the data that supports validity of the hypothesis of economic deprivation. The coefficient $r_{Y, F_{2}}$ is negative as well. This would suggest that the opposite of the hypothesis of opportunity costs holds. Nonetheless, for $r_{Y, F_{2}}$ we do not reject the nullity hypothesis for $\alpha=0.05$; therefore, we conclude that there is not enough evidence in the data to support neither validity nor invalidity of hypothesis of opportunity costs.

\section{DISCUSSION}

The results based on data from selected European countries confirm the conclusions presented in Caruso and Schneider (2011), and Freytag et al. (2011), which describe the relationship between economic environment and individuals' motivation to perpetrate terrorist attacks (the hypothesis of opportunity costs). Gries et al. (2011), who analyzed economic conditions in 7 selected European countries, arrived at similar conclusions. With the exception of Germany, which was not included in the multidimensional analysis, the results were in accordance with findings presented in Gries et al. (2011), and proved the existence of opportunity costs argument in case of Spain a Portugal.

Some results obtained by the analysis are in contrast with what would be expected in the respective cases. For example, the fact that no significant correlation between the factors and the terrorist attack series was found for Greece makes it stand out from the rest of the countries of cluster B. It should be taken into account that terrorist attack series' variability was the second largest for Greece out of all the countries. Additionally, it should be noted that the correlation analysis used for assessment of the connection between the factors and the terrorist attack series only captures linear relations between the variables. This encourages a possible further course of research that would focus on description of the nonlinear relationship between the indicators or the factors and the terrorist attack series.

\section{CONCLUSION}

In the paper, the connection between economic and political indicator variables and terrorist attacks was analyzed using empirical data from 16 European countries. Two hypotheses were proposed the hypothesis of opportunity costs influencing terrorism, and the hypothesis of economic deprivation influencing terrorism. Validity of these hypotheses was studied with the use of empirical data.

For each studied country, the six indicator variables were transformed using factor analysis into two factors that sufficiently described the indicator data set variability. The two factors were used in all subsequent inferences, which lead to a more parsimonious model.

Using the HCA, the countries were divided into clusters based on loadings of the factors. The separate clusters consist of countries with similar loading patterns, which indicates similar economic and political development. Based on the HCA, the 13 countries were split into two clusters. The three remaining countries, Belgium, Luxembourg, and Switzerland, would fall into the two respective clusters only for higher dissimilarity measure values; for this reason, they were studied separately. Cluster B consisted of France, Greece, Portugal, and Spain. Cluster A was further divided into two subclusters; the first right subcluster consisted of Denmark, Finland, Ireland, Italy, the Netherlands, and the United Kingdom, and the second right subcluster consisted of Austria, Norway, and Sweden. Among all of the countries in each cluster, there were slight differences in the loading patterns. These were described separately for each particular case.

Finally, the two hypotheses from the introductory section were studied with the use of correlation analysis. A sufficient piece of evidence that supports validity of the hypothesis of opportunity costs was found in the data for Belgium, France, Italy, the Netherlands, Luxembourg, Portugal, Spain, and the United Kingdom. As for Austria, Denmark, Finland, Greece, Norway, Sweden, and Switzerland, there was not enough evidence to support neither validity nor invalidity of the hypothesis of opportunity costs. The data regarding Ireland actually support invalidity of the hypothesis of opportunity costs. Sufficient evidence that supports validity of the hypothesis of economic deprivation was found in the data for the following countries: Belgium, Ireland, and Switzerland. As far as Austria, Denmark Finland, France, Greece, Italy, the Netherlands, Norway, Portugal, Spain, Sweden, Switzerland, and the United Kingdom are concerned, there was not enough evidence to support neither the validity nor invalidity of the hypothesis of economic deprivation. Data from neither of the countries contained enough evidence that would support invalidity of the hypothesis of economic deprivation. 
The results obtained using factor, cluster, and correlation analyses imply conclusions that can be used in setting up of suitably oriented state economic policies which should support long-term economic growth. Subsequently, this should manifest as improving standards of living of the population, which increases the so-called opportunity costs influencing individuals' behavior and decision-making regarding perpetration of terrorist attacks. Positive economic development of a country naturally leads to a higher demand for work, a lower unemployment rate, and to a higher cost of labor. All of these are natural factors which affect possible economic deprivation of individuals, and their motivation for violent behavior. On that account, the study shows that economic environment is one of the determinants which influence the frequency, and, in consequence, also risks of terrorist attacks in the analyzed countries.

\section{Acknowledgements}

This paper was supported by the Ministry of Education, Youth and Sports of the Czech Republic [SV18-FVL-K101-TEJ].

\section{REFERENCES}

AZAM, J. P. and DELACROIX, A. 2006. Aid and the Delegated Fight Against Terrorism. Review of Development Economics, 10(2): 330-344.

BRAVO, A. B. S. and DIAS, C. M. M. 2006. An Empirical Analysis of Terrorism: Deprivation, Islamism and Geopolitical Factors. Defence and Peace Economics, 17(4): 329-341.

BLOMBERG, B. S. and HESS, G. D. 2008. The Lexus and the Olive Branch: Globalization, Democratization and Terrorism. In: KEEFER, P. and LOAYZA, N. (Eds.). Terrorism, Economic Development, and Political Openness. City of New York, NY: Cambridge University Press, pp. 116-147.

BRIEMAN, L., FRIEDMAN, J. H., OHLSEN, R. A. and STONE, C. J. 1984. Classification and Regression Trees. Belmont, CA: Wadsworth.

CARUSO, R. and SCHNEIDER, F. 2011. The socio-economic determinants of terrorism and political violence in Western Europe (1994-2007). European Journal of Political Economy, 27(1): S37-S49.

FREYTAG, A., KRÜGER, J., MEIERRIEKS, D. and SCHNEIDER, F. 2011. The origins of terrorism: Crosscountry estimates of socio-economic determinants of terrorism. European Journal of Political Economy, 27(1): S5-S16.

GRIES, T., KRIEGER, T. and MEIERRIEKS, D. 2011. Causal Linkages Between Domestic Terrorism and Economic Growth. Defence and Peace Economics, 22(5): 493-508.

GURR, T. R. 1970. Sources of rebellion in western societies: some quantitative evidence. The Annals of the American Academy of Political and Social Science, 391(1): 128-144.

JOHNSON, R. A. and WICHERN, D. W. 2007. Applied Multivariate Statistical Analysis. $6^{\text {th }}$ Edition. Upper Saddle River, NJ: Pearson Prentice Hall.

KRUEGER, A. B. and MALEČKOVÁ, J. 2003. Education, Poverty and Terrorism, Is there a Causal Connection? The Journal of Economic Perspectives, 17(4): 119-144.

MEIERRIEKS, D. and KRIEGER, T. 2011. What Causes Terrorism? Public Choice, 147: 3-27.

ODEHNAL, J. and NEUBAUER, J. 2018. Economic, Security, and Political Determinants of Military Spending in NATO Countries. Defence and Peace Economics, 31(5): 1-15.

OKAFOR G. and PIESSE, J. 2018. Empirical Investigation into the Determinants of Terrorism: Evidence from Fragile States. Defence and Peace Economics, 29(6): 697-711.

PLÜMPER, T. and NEUMAYER, E. 2009. The friend of my enemy is my enemy. International Alliances and International Terrorism, 49(1): 75-69.

RAO, R. K. 1973. Linear Statistical Inference and its Applications. New York, NY: John Wiley \& Sons, Inc. SHAHBAZ, M. 2013. Linkages between Inflation, Economic Growth and Terrorism in Pakistan. Economic Modelling, 32: 496-506.

\section{Contact information}

Martin Tejkal: martin.tejkal@unob.cz

Jakub Odehnal: jakub.odehnal@unob.cz

Jaroslav Michálek: jaroslav.michalek@unob.cz 